\title{
Research for Model Based on Petri Nets about Maintenance and Support of Military Aviation Equipment
}

\author{
Zheng Wang \\ Qingdao Branch of Naval \\ Aeronautical Engineering Academy \\ Qingdao,China \\ w_zheng@public.qd.sd.cn
}

\author{
Jianhua Song \\ Qingdao Branch of Naval \\ Aeronautical Engineering Academy \\ Qingdao,China
}

\author{
Xingdong Zhu \\ Qingdao Branch of Naval \\ Aeronautical Engineering Academy \\ Qingdao,China
}

\begin{abstract}
In this paper, the model based on Petri Nets about maintenance and support of military aviation equipment is researched. And this paper analyzes its process and puts forward a simulation model based on Petri net. This model not only considers most factors in the process, but also appends other elements easily. The model can be applied to the research on maintenance and support of military aviation equipment, or be used for a part of higher level military simulation system.
\end{abstract}

Keywords- Petri Nets; maintenance and support; Military Aviation Equipment; work flow; model

\section{INTRODUCTION}

Maintenance and support of military aviation equipment is a series of technique and management activities, as well as the guarantee resource, which is necessary for carrying out effectively to make sure these activities. These activities can keep and recover technique status in good condition, make sure proper operation and usage in order to give full play of fight performance of military aviation. Practice in modern war has proven that, maintenance and support of military aviation equipments have direct effects on equipment fight capacity play. Maintenance level of military aviation equipments is decided by designed characteristics of equipments, such as reliability, maintainability, testability and survivability, and is also closely related with service environment, people operation and plan guarantee resource of military aviation after deployed to troops. Interplay of all above factors decides the battle effectiveness of military aviation. It is a complex dynamics, while operated according to confirm regulations, as a result, the model of this process becomes one of the most important problem in maintenance research of military aviation equipment . This paper analyzes character and process of maintenance and support of military aviation equipment, and develops a model by Petri nets which is object-oriented, supplying reference for research of maintenance and support of military aviation equipment.

\section{ANALYSIS OF MAINTENANCE AND SUPPORT OF MILITARY AVIATION EQUIPMENT}

Maintenance and support of military aviation equipment includes three parts: Operation support, maintenance works and support engineering shown in figure 1.

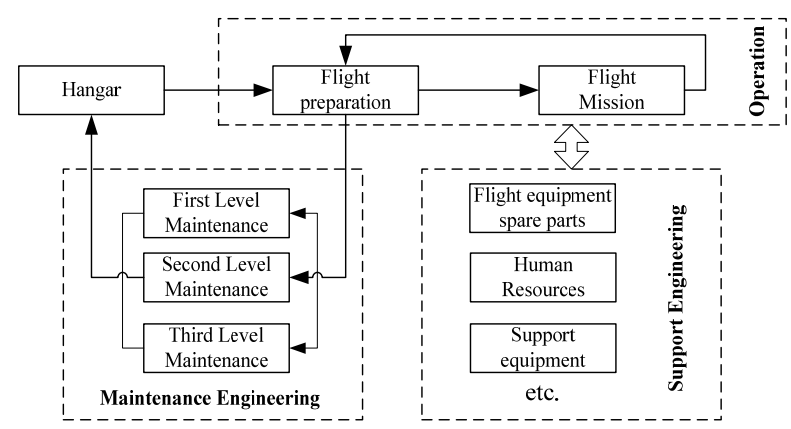

Figure1. Component of maintenance and support process

In operation, aviation equipment makes flight preparation and completing the task according to mission requirements. After the end of each mission, the maintenance personnel make the corresponding level of maintenance according to Fault degree, and get security resources through the related security department. In the actual maintenance support process of aviation equipment, three part of work is interaction and overlapping, because of the randomness of the aviation equipment failure and the diversity of the task. In order to ensure smooth completion of the mission and the fastest recovery of fault equipment, there is competition between the personnel and support equipment in the aviation security and the use of equipment maintenance. At the same time, when assigning aviation equipment for tasks, there is a priority of the decision according to equipment condition. Because of the uncertain relationship between each other, we cannot get the desired outcome only by modeling one part of factors. It is necessary to model the whole maintenance support process of aviation equipment.

\section{MODUlE OF MAINTENANCE AND USAGE OF AVIATION EQUIPMENT}

Petri nets is model and analysis tool for distributed systems. It is convenient to describe relationships in systems, such as sequence, supervene, collision and synchronization. It is first suggested by Germany scholar C.A.Petri in 1962. The essence of Petri net is considering system structure and dynamical property by graph theory, and Petri net is suited to model and analyze asynchronous concurrent systems. Petri net can describe asynchrony, concurrence, distribution, collision and share of resource in maintenance of aviation equipment well. The Expanded object-oriented Petri net 
proposed in [3] and [4] can describe complex situation well, such as limited maintenance human and resource, maintenance applying for queuing up, and maintenance priority, and has good expansibility.

\section{A. Extraction and mutual relationship of simulation entity}

According the actual process of maintenance and support, the model can be divided into four modules: flight command center, aviation equipment, maintenance command center and the flight equipment spare parts warehouse. Flight command center is responsible for transmitting to lower levels the task of aviation equipment orders, which is supposed to be realized by the aviation equipment; according to the mission and state of aviation equipment, maintenance service command center do personnel deployment of maintenance personnel and safeguard equipment, and application of the materials spare parts needed; the materials spare parts warehouse is responsible for the supply of spare parts and materials storage transport. All entities cooperate with each other to complete all the task of use, maintenance and security. Through the UML, Figure 2 show main task and interaction of each module by case diagrams, where solid lines refer to connection relationship and the dotted line inclusion relation.

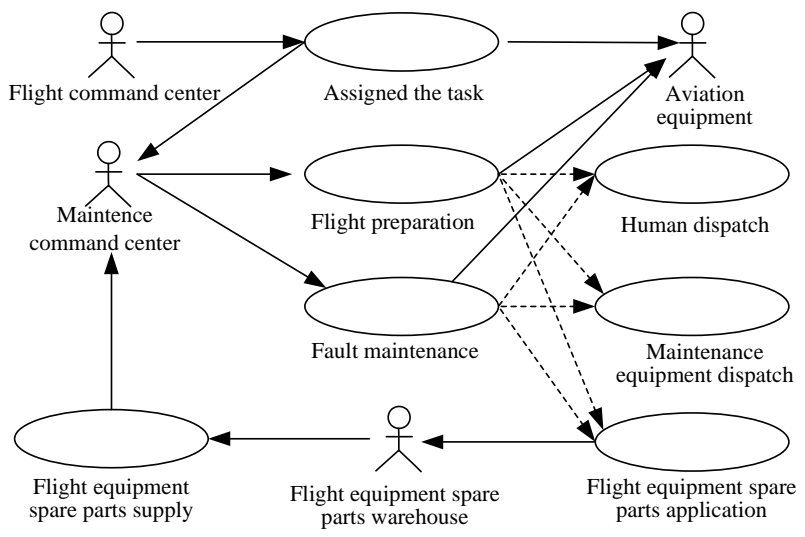

Figure2. Case diagram of Maintenance and support module

\section{B. Module of flight command center}

Figure 3 is module of flight command center, where $\mathrm{p} 1$ is the overall mission number, $\mathrm{t} 1$ for Task produce, $\mathrm{p} 2$ to produced task. According to the scheduled flight plan, when we need to give the task, $\mathrm{t} 1$ trigs, representing of flight task token moved to p2 from p1, waiting for aviation equipment modules transmitted in.

Because of differences of maintenance requirements for each task, $\mathrm{t} 1$ uses different colors to show different needs of security personnel and support installation; in addition, execution time of each flight the task is not identical either, so $\mathrm{t} 1$ gives each token a time as classifying tasks.

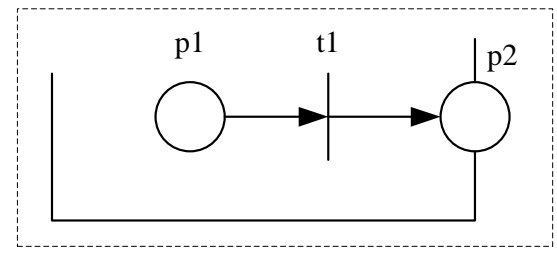

Figure3. Module of flight command center

\section{Module of aviation equipment}

Equipment model involved operation support and maintenance works in maintenance support process. Figure 4 is the model diagram of aviation equipment, where p3 is task given, p32 ready to apply for, p4 preparing to wait for, p5 preparing response, $\mathrm{p} 6$ the preparation process, $\mathrm{p} 7$ preparing end signals, p8 executing assignment, p9 for maintenance waiting, p10 for maintenance application, p11 for maintenance response, $\mathrm{p} 12$ for in maintenance, $\mathrm{p} 13$ for the maintenance end signal, p14 end for maintenance, and p15 for aviation equipment state.

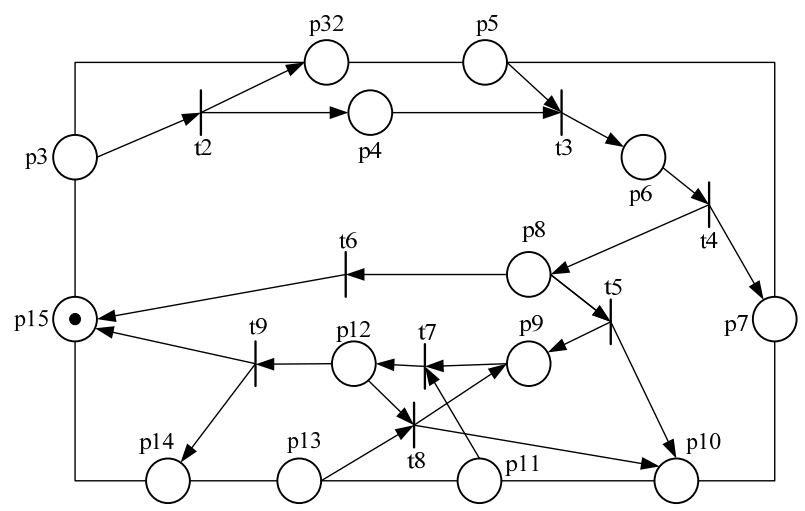

Figure 4 Module of aviation equipment

When token representing flight tasks comes into p3, aviation equipment sends to maintenance service command center the signal to apply for preparing according to a flight mission requirements, and after responded, aviation equipment gets into the preparation process. When finished, aviation equipment sends out an end signal. After the task, if aviation equipment has any failure, it will enter the repair process: $t 5$ will Shading classification according to the fault requirement, and sends out application of the fault maintenance. After getting response, equipment is brought into the maintenance state, and then equipment gets into the idle state, waiting for the new task. In the course of maintenance, if receives signal for maintenance suspended, equipment maintenance process return to maintenance wait states from maintenance states, waiting for allocation of the maintenance personnel and maintenance equipment.

\section{Module of maintenance command center}

Maintenance command center module, including operation support and maintenance engineering of personnel and scheduling of all support equipment distribution, and is 
responsible for application materials required for flight equipment spare parts. Figure 5 is the model diagram of maintenance command center, where p16 is signal of applications for maintenance, p17 is response signal of maintenance, p18 is the end signal of maintenance, p19 is human and equipment for maintenance task, p20 is human and equipment can be used, p23 is signal of preparing to apply, p22 is human and equipment in preparation, p25 is signal of preparing response, p26 is signal of preparing end. In order to express the process of preparation and maintenance personnel and equipment for the competition, p21 and p24 are imported. P21 is state of resources are available and p24 is signal of suspension of maintenance.

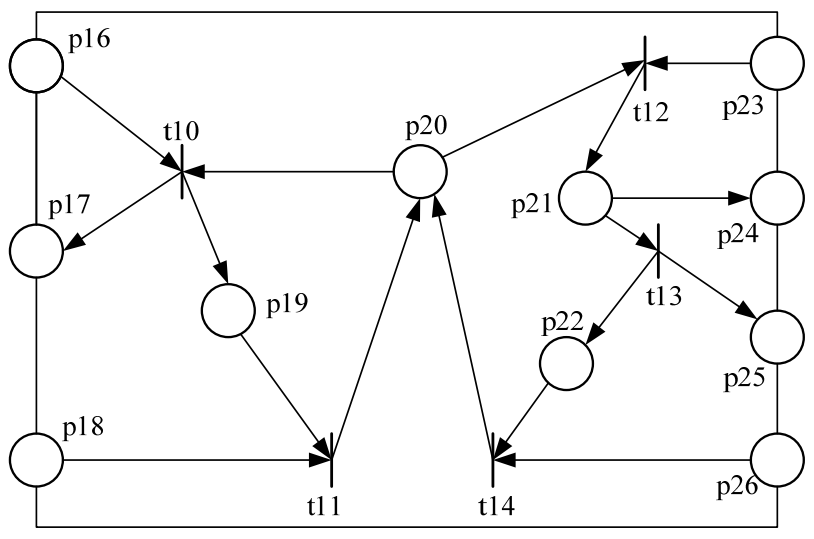

Figure 5 Module of maintenance command center

When the module receives the signal of applications for maintenance, t10 will allocate the resources needed according to the type of failure and issue a response signal of maintenance. When the maintenance is over and the end signal of maintenance is received, maintenance human and equipment will enter into p20 again. maintenance human and equipment are in the available state. When the module receives the signal of applications for preparing, it is the same basic as for maintenance. It is different from that if resources are insufficient to prepare for flight, in order to ensure the conduct of the flight, module will issue a stop signal for maintenance by p24, to recover part of the maintenance resources.

\section{E. Module of flight equipment spare parts warehouse}

Figure 6 is the model diagram of flight equipment spare parts warehouse, mostly including the deployment of flight equipment spare parts and materials transshipment, where p27 is signal of application for flight equipment spare part, p28 is response signal of application for flight equipment spare part, p29 is existing stock, p30 is stock status p31 is transit transport cycle. When the signal of application for flight equipment spare part, the flight equipment will be deployed based on signals from existing stocks. If the existing stock below the minimum inventory requirements, application for transfer from upper department will be conducted. T18 and t17 give different delay for different levels of the supply

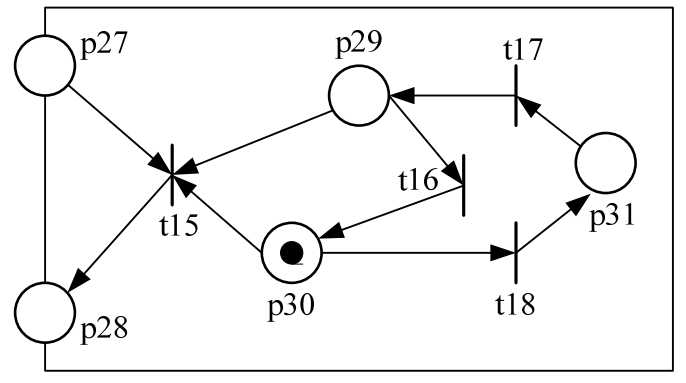

Figure 6 Module of flight equipment spare parts warehouse

\section{F. Module of maintenance support process of aviation equipment}

Figure 7 is the model diagram for operation, maintenance and support process of aviation equipment spare parts warehouse. Flight command center assign the task to equipments in good condition by t19. Aviation equipment issue signal of application for flight preparing, and the signal is transmitted to maintenance command center and flight equipment spare part warehouse. When human, equipment and aviation materials meet the requirements all, aviation equipments receive the response signal of preparing transmitted by t22, it will be in the preparing process. When the process id over, Aviation equipment issue signal of preparing over, and the process of preparing is end. The process of fault is the same as preparing process. $t 21$ is the maintenance stop signal transmitting. Only when the human and resources are insufficient to ensure preparing work, the signal will be issued by maintenance command center. The maintenance process of corresponding aviation equipment and human and support resource will be recovery.

Because all events are included in each module, when multiple aviation equipment participate in mission, only need to add in the model number of equipment modules corresponding to. When the need to add new types of personnel, types of support resources, need only be set in the corresponding module.

\section{CONCLUSION}

The paper proposes maintenance process model of aviation equipment, including the operation maintenance, the breakdown maintenance and support engineering for the aviation equipment. Through the simulation of this model, we get combat perfectness ratio of aviation equipment, utilization ratio of maintenance personnel and the equipment, and the supply of spare parts and materials, and so on. The model has better scalability, and can be used in aviation equipment maintenance research, as well as a higher level of military system simulation component of use. 


\section{REFERENCES}

[1] Hengxi Zhang, Jiayuan Zhu, Jilian Guo. "Introduction to Military Aircraft Model Development”, [M] Bei Jing: National Defense Industry Press, pp. 348-349, (2004). (In Chinese)

[2] Hengwei Wang. "Modeling and Simulation” [M], Bei Jing: Science Press, pp. 348-349, (2004). (In Chinese)

[3] Chongyi Ruan. "Petri Net Theory and Application" [M], Bei Jing: Electronics Industry Press, pp. 148-150, (2004). (In Chinese)

[4] Xiaoyue Wu, Jichang Sha, . "Reliability analysis of flexible manufacturing systems GOOPN model” [J], Computer Integrated Manufacturing System, 2000, 6:65 68. (In Chinese)
[5] Xiaoyue Wu, Weiming Zhang, Jichang Sha, . "GOOPN model of Communications network reliability analysis" [J], Systems Engineering and Electronics, 2000, 22:84 90. (In Chinese)

[6] MuDer Jeng, WeiZhao Lu. Extension of UML and Its Conversion to Petri Nets for Semiconductor Manufacturing Modeling [C]// Proceedings of the 2002 IEEE International Conference on Robotics\& Automation, Washington. DC, 2002:3175-3180.

[7] J E Hong, D H Bae. Software Modeling and Analysis Using a Hierarchical Object-Oriented Petri Net [J]. Information Sciences (S00200255), 2000, 130(1-4): 133-64.

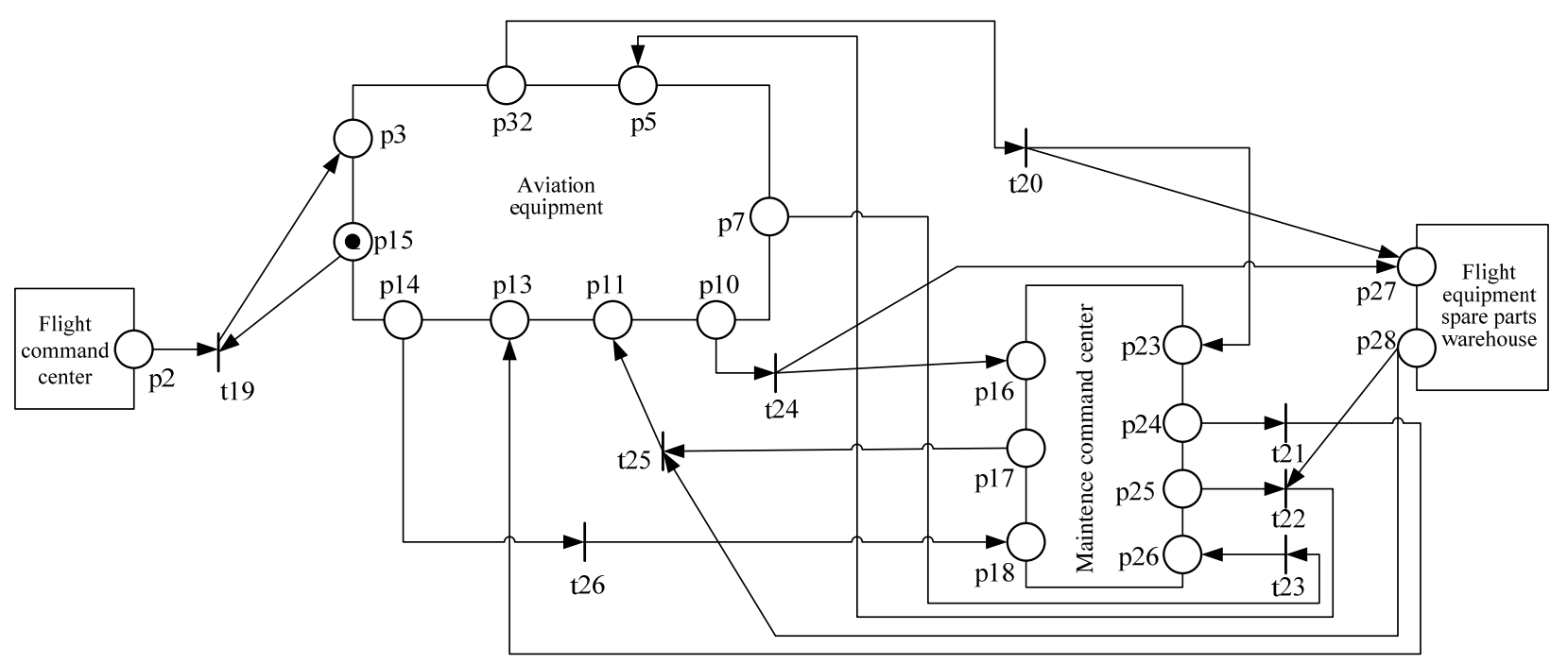

Figure 7 Module of maintenance and support process for aviation equipment 